\title{
Decision and Coordination of Cross-Border E-Commerce Supply Chain: Based on Four Modes of Cooperation
}

\author{
Wei Yan, ${ }^{1}$ Huijun Zhou $\mathbb{D}^{2},{ }^{2}$ and Hui Li ${ }^{3}{ }^{3}$ \\ ${ }^{1}$ Logistics Engineering College, Shanghai Maritime University, Shanghai 201306, China \\ ${ }^{2}$ School of Economics and Management, Shanghai Maritime University, Shanghai 201306, China \\ ${ }^{3}$ School of Management, Guangxi University for Nationalities, Nanning 530006, China \\ Correspondence should be addressed to Huijun Zhou; hjzhou@shmtu.edu.cn and Hui Li; lihui_1011@163.com
}

Received 6 February 2021; Accepted 26 April 2021; Published 7 May 2021

Academic Editor: Lu Zhen

Copyright ( $\odot 2021$ Wei Yan et al. This is an open access article distributed under the Creative Commons Attribution License, which permits unrestricted use, distribution, and reproduction in any medium, provided the original work is properly cited.

\begin{abstract}
Due to the explosive growth trend of cross-border e-commerce, a series of problems such as high transportation costs and insufficient publicity are to be solved urgently by researching on supply chain from both decision-making and coordination perspectives. Under the four-incomplete cooperative Stackelberg decision-making modes of cross-border e-commerce supply chain members, the transportation cost of overseas suppliers and the promotion strategy of domestic retailers determine the profit of the supply chain together and further influence the choice of the optimal decision-making plan. Furthermore, the Shapley value method and full cooperative income incremental sharing mechanism are used to redistribute the profits under different cooperation modes, and it is expected to provide scientific decision-making reference for domestic cross-border e-commerce enterprises to rationally choose cooperative relationships.
\end{abstract}

\section{Introduction}

With the increasing popularity of Internet technology and the improvement in payment system and the influence of new coronavirus (COVID-19), more and more consumers are buying imported goods through cross-border e-commerce platforms. Therefore, the import cross-border e-commerce shows an explosive growth trend. According to the data released by China E-Commerce Research Center (100\%) EC, the transaction volume of China's import crossborder e-commerce market in 2019 is 2.47 trillion yuan, an increase of nearly $30 \%$ over 2018 , and it is expected to reach 29.66 trillion yuan in 2020 .

The vigorous development of cross-border e-commerce has not only greatly enriched the product supply in the domestic market but also exposed a series of problems in the supply chain management of cross-border e-commerce in China [1]. On the one hand, the high transportation cost of cross-border e-commerce (accounting for about 20\% 30\% of the total cost) not only increases the purchase cost of consumers but also reduces the profits of middlemen; on the other hand, due to the insufficient publicity of cross-border e-commerce, the single channel of commodity promotion, it is difficult for retailers to avoid the third-party e-commerce platform, which increases the intermediate links and weakens the profits of domestic cross-border e-commerce enterprises ability [2].

Therefore, in order to solve the vicious competition cycle caused by the non-cooperative game between overseas e-commerce and domestic retailers, it is urgent to study the influence of changes in transportation costs and propaganda strategy on the pricing strategy and member profit distribution of cross-border e-commerce supply chain. In this paper, we focus on the following question: first, in the decentralized and centralized scenario, how do the members in the cross-border e-commerce supply chain make decisions; second, how do the influences of transport cost and advertising cost on the decisions; finally, which can coordination mechanism effectively balance the stakeholders to make the total performance maximization.

From the existing literature, the research related to the above contents mainly focuses on the following two aspects: 
(1) Influence of advertising strategy on supply chain decision-making

Based on the supply chain of manufacturers and retailers, study the problems of price promotion and advertising strategy of manufacturers [3]; considering the problem that advertising investment restricts market demand, discuss the optimal decisionmaking and coordination mechanism under the mode of concentration and dispersion of single- and double-channel supply chain [4]; by using the consumer demand function, explore the cooperative advertising and supply chain coordination of pricing [5]; from the perspective of the dynamic influence of advertising on market demand, discuss the issues of manufacturer's advertisement competition and manufacturer-retailer channel price competition [6]; on the basis of the influence of innovation and advertising on the demand of commodity market, probe into the optimal decision-making of supply chain members under cooperative and non-cooperative mechanisms [7].

(2) Influence of transport costs on supply chain decision-making

To reduce transport costs and divide the crossborder e-commerce costs into management cost, logistics cost, and sale cost [8]; different supply chain logistics cost-sharing strategies are applied to explore the influence on supply chain profit through the study of the impact of tariffs, transport costs on global value chains, find that the rise of trade costs such as tariffs will increase the investment of enterprises and the purchase price of raw materials [9]; based on the game model of cross-border supply chain led by retailers, introduce the index of tariff and international transportation cost to analyze the influence of tariff change in commodity pricing and member profit of cross-border supply chain [10]; the optimized countermeasure is applied to how to use overseas warehouse to realize the timeliness of crossborder logistics in order to reduce transportation cost; consider that logistics cost has an important impact on cross-border e-commerce imports and then make a deep study on the cost optimization of cross-border e-commerce logistics $[11,12]$.

(3) Influence of coordination contract on supply chain decision-making

Through the supply chain contract to coordinate the decision-making behavior among the members, the profit can be optimized. Under the uncertain environment, Peng et al. [13] proposed a unidirectional option contract and bidirectional option contract to coordinate supply chain members and analyze their different impacts on members. Xu et al. [14] introduced the revenue sharing and cost sharing into designing an improved contract to coordinate the participates effectively. Designed the decision model for the nongreen and green products pricing to ensure the supply chain's participants achieve Pareto improvement. Dai et al. [15] designed the deliverytime-dependent quantity flexibility contract and late-rebate contract to balance the stakeholders under the uncertain demand. Liu et al. [16] discussed whether an option contract coordinated the members effectively when express delivery was provided from retailer.

Through the analysis of the above literature, it is found that the research methods of supply chain are rich and mature, which provide a specific reference for this paper from the technical point of view. However, most of the research results on supply chain publicity and transportation costs are concentrated in the traditional production enterprises. There are few studies on the influence of publicity strategy and transportation cost on cross-border e-commerce pricing strategy. There is little research on the influence of supplier retailer cooperation mode on supply chain pricing at home and abroad.

Based on this, from the perspective of cross-border e-commerce supply chain pricing and publicity strategies under different cooperation modes, this paper discusses the coordination of cross-border e-commerce supply chain pricing strategy and member profit distribution, as well as how crossborder e-commerce enterprises cope with the impact of changes. In terms of transportation cost and publicity level, this paper makes optimization decisions for cross-border e-commerce supply chain members to optimize cross-border e-commerce supply chain e-commerce supply chain member's profit. Cross-border e-commerce supply chain provides a scientific reference for the rapid and healthy development of China's e-commerce industry.

\section{Model Hypothesis}

Hypothesis 1. Domestic retailers use a variety of promotional tools to enable consumers to buy their goods, and according to [17], the demand function is not only affected by retail price but also by propaganda strategy, so suppose the demand function $d\left(p, \theta_{2}\right)=a-p+\lambda \theta_{2}$, in which " $a$ " for the potential market demand, " $p$ " for the retail prices per unit product of domestic retailers, " $\lambda$ " for consumer sensitivity to retailer propaganda $(\lambda>0)$, and " $\theta_{2}$ " for the domestic retailer's propaganda strategy.

Hypothesis 2. According to [18], wholesale price for unit products of overseas suppliers is $w$, and the transportation cost per unit product is a linear relationship of monotone decreasing with the volume of transport, so $c_{d}=c-\rho d\left(p, \theta_{2}\right)$, in which " $\rho$ " is for marginal transport cost factor for unit product $(\rho>0)$ and " $c$ " is fixed transport costs per unit product (i.e., fixed transport costs per unit product regardless of economies of scale). 
Hypothesis 3. Domestic retailers promote the extra cost of product propaganda. Assume the publicity costs of domestic retailers $C\left(\theta_{2}\right)=K_{2} \theta_{2}^{2} / 2$, in which $K_{2}$ indicates the scale of domestic retailer propaganda activity.

Hypothesis 4. If only the cost of transportation of products from overseas suppliers to domestic suppliers is considered, the cost of transportation from domestic retailers to consumers is ignored.

Hypothesis 5. Overseas suppliers and domestic retailers are completely rational persons, and the decision information of both sides is completely symmetrical.

\section{Construction of Cross-Border E-Commerce Supply Chain Decision Model}

In view of the space limitation, this paper mainly studies the decision-making problem under the two-level cross-border supply chain cooperation mode composed of a single overseas supplier and a single domestic retailer; that is, the overseas supplier sells the goods to the domestic retailer and bears the transportation cost. Clearly, the overseas supplier and the domestic retailer form a kind of Stackelberg cooperation relationship, and the overseas supplier is the decision-maker, while the domestic retailer is the decision follower.

By constructing decision-making models of non-cooperation, semi-cooperation (including two kinds of one-way cooperation modes of retailers sharing transportation cost and supplier sharing propaganda cost), and full cooperation between overseas suppliers and domestic retailers, it can clarify the influence of pricing and propaganda strategy on profit of cross-border e-commerce supply chain and provide scientific decision reference for rational selection of cooperative relationship.

Furthermore, the introduction of Shapley value method and the incremental benefit sharing mechanism for full cooperation is beneficial to the rational redistribution of profits of overseas suppliers and domestic retailers under different cooperation modes.

3.1. Decision-Making in the Non-Cooperative Model of Suppliers and Retailers $(N)$. Under this model, overseas suppliers usually set wholesale prices $w^{N}$ first, and then, domestic retailers determine retail prices $P^{N}$ and publicity strategies $\theta_{2}^{N}$.

Thus, the profits of overseas suppliers and domestic retailers under the non-cooperation mode are as follows:

$$
\begin{aligned}
& \pi_{m}^{N}=(w-c)\left(a-p+\lambda \theta_{2}\right)+\rho\left(a-p+\lambda \theta_{2}\right)^{2}, \\
& \pi_{r}^{N}=(p-w)\left(a-p+\lambda \theta_{2}\right)-\frac{1}{2} K_{2} \theta_{2}^{2} .
\end{aligned}
$$

Proposition 1. Under the non-cooperation structure of overseas suppliers and domestic retailers, the optimal decision of cross-border e-commerce supply chain is

$$
\begin{aligned}
& w^{N *}=\frac{2(a+c-a \rho) K_{2}-(a+c) \lambda^{2}}{2\left[(2-\rho) K_{2}-\lambda^{2}\right]}, \\
& P^{N *}=\frac{(c+3 a-2 a \rho) K_{2}-(a+c) \lambda^{2}}{2\left[(2-\rho) K_{2}-\lambda^{2}\right]}, \\
& \theta_{2}^{N *}=\frac{(a-c) \lambda}{2\left[(2-\rho) K_{2}-\lambda^{2}\right]} .
\end{aligned}
$$

Proof. The reverse induction method is used to solve the problem.

Firstly, determine the Hessian matrix for the domestic retailer profit function $\pi_{r}^{N}$ :

$$
H\left(p, \theta_{2}\right)=\left[\begin{array}{cc}
\frac{\partial^{2} \pi_{r}^{N}}{\partial\left(P^{N}\right)^{2}} & \frac{\partial^{2} \pi_{r}^{N}}{\partial P^{N} \partial \theta_{2}^{N}} \\
\frac{\partial^{2} \pi_{r}^{N}}{\partial \theta_{2}^{N} \partial P^{N}} & \frac{\partial^{2} \pi_{r}^{N}}{\partial\left(\theta_{2}^{N}\right)^{2}}
\end{array}\right]=\left[\begin{array}{cc}
-2 & \lambda \\
\lambda & -K_{2}
\end{array}\right] .
$$

It is not difficult to see from the above Hessian matrix: $\left(\partial^{2} \pi_{r}^{N} / \partial\left(P^{N}\right)^{2}\right)=-2<0$ and $|H|=2 K_{2}-\lambda^{2}>0 ; \pi_{r}^{N}$ is a strictly joint concave function about $P^{N}$ and $c \theta_{2}^{N}$, and there is an optimal solution to maximize profits.

Secondly, first-order partial derivative conditions are as follows: $\overline{p^{N}}=\left((a+w) K_{2}-w \lambda^{2} / 2 K_{2}-\lambda^{2}\right)$ and $\overline{\theta_{2}^{N}}=((a-$ $\left.w) \lambda / 2 K_{2}-\lambda^{2}\right)$ substituted into formula (1), and the secondorder derivative function of profit function of overseas suppliers can be obtained as $\left(\partial^{2} \pi_{m}^{N} / \partial\left(w^{N}\right)^{2}\right)=-\left(2 K_{2}[(2-\right.$

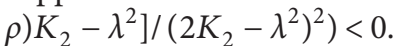

It can be seen that $\pi_{m}^{N}$ is a strict concave function about $w^{N}$, and there is an optimal solution to maximize profit, and thus, the first-order partial derivative condition is $w^{N *}=\left(2[a(1-\rho)+c) K_{2}-(a+c) \lambda^{2} / 2\left[(2-\rho) K_{2}-\lambda^{2}\right]\right)$; decisions available to domestic retailers are $P^{N *}=((c+3 a-$ $\left.2 a \rho) K_{2}-(a+c) \lambda^{2} / 2\left[(2-\rho) K_{2}-\lambda^{2}\right]\right)$ and $\theta_{2}^{N *}=((a-c) \lambda /$ $\left.\left[2(2-\rho) K_{2}-\lambda^{2}\right]\right)$. Now, the commodity market demand and the profits of the members of the cross-border e-commerce supply chain are

$$
\begin{aligned}
d^{N *} & =\frac{(a-c) K_{2}}{2\left[(2-\rho) K_{2}-\lambda^{2}\right]}, \\
\pi_{m}^{N *} & =\frac{(a-c)^{2} K_{2}}{4\left[(2-\rho) K_{2}-\lambda^{2}\right]}, \\
\pi_{r}^{N *} & =\frac{(a-c)^{2}\left(2 K_{2}-\lambda^{2}\right) K_{2}}{8\left[(2-\rho) K_{2}-\lambda^{2}\right]^{2}} .
\end{aligned}
$$

From the above equilibrium results, we can see that the pricing of cross-border e-commerce supply chain is inversely proportional to the unit transportation cost, while the propaganda strategy of domestic retailers and the profits of supply chain members are all proportional to the unit 
transportation cost; that is, $\left(\partial w^{N *} / \partial \rho\right)<0, \quad\left(\partial p^{N *} / \partial \rho\right)<0$, $\left(\partial \theta_{2}^{N *} / \partial \rho\right)<0,\left(\partial \pi_{m}^{N *} / \partial \rho\right)<0,\left(\partial \pi_{r}^{N *} / \partial \rho\right)<0$.

3.2. Decision-Making under the One-Way Cooperation Mode for Retailers Sharing Suppliers' Transportation Costs (M). Based on their own profit maximization under this mode, domestic retailers will share the transportation costs of overseas suppliers in proportion of $\theta_{m}\left(0 \leq \theta_{m} \leq 1\right)$.

Obviously, when $\theta_{m}=0$, domestic retailers are unwilling to share the transportation costs of overseas suppliers, and when $\theta_{m}=1$, domestic retailers are willing to share the full transportation costs of overseas suppliers.

Under established $\theta_{m}$, overseas suppliers usually set wholesale prices $w^{M}$, and then, domestic retailers determine retail price $P^{M}$ and publicity strategy $\theta_{2}^{M}$.

Therefore, the profits of overseas suppliers and domestic retailers under this cooperation model are

$$
\begin{aligned}
& \pi_{m}^{M}=\left\{w-\left(1-\theta_{m}\right)\left[c-\rho\left(a-p+\lambda \theta_{2}\right)\right]\right\}\left(a-p+\lambda \theta_{2}\right), \\
& \pi_{r}^{M}=\left\{p-w-\theta_{m}\left[c-\rho\left(a-p+\lambda \theta_{2}\right)\right]\right\}\left(a-p+\lambda \theta_{2}\right)-\frac{1}{2} K_{2} \theta_{2}^{2} .
\end{aligned}
$$

Proposition 2. Under the one-way cooperation mode of domestic retailers sharing the transportation cost of overseas suppliers, the optimal decision of cross-border e-commerce supply chain is as follows:

$$
\begin{aligned}
& \theta_{m}^{M *}=1 \\
& w^{M *}=\frac{a-c}{2} \\
& p^{M *}=\frac{[c+a(3-4 \rho)] K_{2}-(a+c) \lambda^{2}}{2\left[2(1-\rho) K_{2}-\lambda^{2}\right]} \\
& \theta_{2}^{M *}=\frac{(a-c) \lambda}{2\left[2(1-\rho) K_{2}-\lambda^{2}\right]}
\end{aligned}
$$

Proof. The reverse induction method is used to solve the problem.

Firstly, determine Hessian matrix for the domestic retailer profit function $\pi_{r}^{M}$ :

$$
\begin{aligned}
H\left(p, \theta_{2}\right) & =\left[\begin{array}{cc}
\frac{\partial^{2} \pi_{r}^{M}}{\partial\left(P^{M}\right)^{2}} & \frac{\partial^{2} \pi_{r}^{M}}{\partial P^{M} \partial \theta_{2}^{M}} \\
\frac{\partial^{2} \pi_{r}^{M}}{\partial \theta_{2}^{M} \partial P^{M}} & \frac{\partial^{2} \pi_{r}^{M}}{\partial\left(\theta_{2}^{M}\right)^{2}}
\end{array}\right] \\
= & {\left[\begin{array}{cc}
-2\left(1-\rho \theta_{m}\right) & \lambda\left(1-\rho \theta_{m}\right) \\
\lambda\left(1-\rho \theta_{m}\right) & -K_{2}+2 \lambda^{2} \rho \theta_{m}
\end{array}\right] . }
\end{aligned}
$$

It is not difficult to see from the above Hessian matrix: $\left(\partial^{2} \pi_{r}^{M} / \partial\left(P^{M}\right)^{2}\right)=-2\left(1-\rho \theta_{m}\right)<0$ and $|H|=2 K_{2}(1-$ $\left.\rho \theta_{m}\right)-\lambda^{2}>0 ; \pi_{r}^{M}$ is a strictly joint concave function about $P^{M}$ and $\theta_{2}^{M}$, and there is an optimal solution to maximize profits.

Secondly, first-order partial derivative conditions are as follows: $\overline{p^{M}}=\left(K_{2}\left[a+w+(c-2 a \rho) \theta_{m}\right]-\lambda^{2}\left(w+c \theta_{m}\right) /\right.$ $\left.2 K_{2}\left(1-\rho \theta_{m}\right)-\lambda^{2}\right)$ and $\overline{\theta_{2}^{M}}=\left(\lambda\left(a-w-c \theta_{m}\right) / 2 K_{2}(1-\right.$ $\left.\rho \theta_{m}\right)-\lambda^{2}$ ) substituted into formula (2), and the secondorder derivative function of profit function of overseas suppliers can be obtained as $\left(\partial^{2} \pi_{m}^{M} / \partial \quad\left(w^{M}\right)^{2}\right)=$ $-\left(2 K_{2}\left\{K_{2}\left[2-\rho\left(1+\theta_{m}\right)\right]-\lambda^{2}\right\} /\left[2 K_{2}\left(1-\rho \theta_{m}\right)-\lambda^{2}\right]^{2}\right)<0$.

It can be seen that $\pi_{m}^{M}$ is a strict concave function about $w^{M}$, and there is an optimal solution to maximize profit; thus, the first-order partial derivative condition is $w^{M}\left(\theta_{m}\right)=\left(2 K_{2}\left[a(1-\rho)+c\left(1-2 \theta_{m}+\rho \theta_{m}^{2}\right)\right]-\lambda^{2}(a+c-\right.$ $\left.\left.2 c \theta_{m}\right) / 2\left\{K_{2}\left[2-\rho\left(1+\theta_{m}\right)\right]-\lambda^{2}\right\}\right)$, and decisions available to domestic retailers are $p^{M}\left(\theta_{m}\right)$ and $\theta_{2}^{M}\left(\theta_{m}\right)$. The profits of domestic retailers are $\pi_{r}^{M}\left(\theta_{m}\right)=\left((a-c)^{2} K_{2}\left[2 K_{2}(1-\right.\right.$ $\left.\left.\left.\rho \theta_{m}\right)-\lambda^{2}\right] / 8\left\{K_{2}\left[2-\rho\left(1+\theta_{m}\right)\right]-\lambda^{2}\right\}^{2}\right)$.

Moreover, according to $\left(\partial^{2} \pi_{r}^{M}\left(\theta_{m}\right) / \partial\left(\theta_{m}\right)^{2}\right)<0, \pi_{r}^{M}$ is a strict concave function about $\theta_{m}$, which has the optimal solution to maximize the profit of domestic retailers, so substituting the first-order partial derivative condition $\theta_{m}^{M *}=1$ into formula $w^{M}\left(\theta_{m}\right), p^{M}\left(\theta_{m}\right)$, and $\theta_{2}^{M}\left(\theta_{m}\right)$, the optimal decisions of overseas suppliers and domestic retailers are $w^{M *}, p^{M *}$, and $\theta_{2}^{M *}$.

Finally, it can be concluded that the market demand of commodities and the profits of each member of cross-border e-commerce supply chain are as follows:

$$
\begin{aligned}
& d^{M *}=\frac{(a-c) K_{2}}{2\left[2(1-\rho) K_{2}-\lambda^{2}\right]}, \\
& \pi_{m}^{M *}=\frac{(a-c)^{2} K_{2}}{4\left[2(1-\rho) K_{2}-\lambda^{2}\right]}, \\
& \pi_{r}^{M *}=\frac{(a-c)^{2} K_{2}}{8\left[2(1-\rho) K_{2}-\lambda^{2}\right]} .
\end{aligned}
$$

It can be seen that, in the semi-cooperative mode of retailers sharing the transportation costs with suppliers, domestic retailers are generally willing to share the total transportation costs of overseas suppliers in order to maximize their profits. Also, the cost of transportation will eventually be passed on to consumers by domestic retailers.

3.3. Decision-Making under the One-Way Cooperation Model for Suppliers Sharing Retailers' Publicity Costs (R). Based on their own profit maximization under this mode, most of the overseas suppliers in this model will share the publicity cost with domestic retailers in proportion of $\theta_{r}\left(0 \leq \theta_{r} \leq 1\right)$.

Obviously, when $\theta_{r}=0$, overseas suppliers are unwilling to share the promotional costs of domestic retailers; when $\theta_{r}=1$, overseas suppliers are willing to share the full promotional costs of domestic retailers. Under established condition $\theta_{r}$, overseas suppliers usually set wholesale prices $w^{R}$ first, and then, domestic retailers determine retail prices $P^{R}$ and publicity strategies $\theta_{2}^{R}$. 
Therefore, the profits of overseas suppliers and domestic retailers under this cooperation model are

$$
\begin{aligned}
& \pi_{m}^{R}=(w-c)\left(a-p+\lambda \theta_{2}\right)+\rho\left(a-p+\lambda \theta_{2}\right)^{2}-\frac{1}{2} \theta_{r} K_{2} \theta_{2}^{2}, \\
& \pi_{r}^{R}=(p-w)\left(a-p+\lambda \theta_{2}\right)-\frac{1}{2}\left(1-\theta_{r}\right) K_{2} \theta_{2}^{2} .
\end{aligned}
$$

Proposition 3. Under the one-way cooperation mode of overseas suppliers sharing the propaganda cost of domestic retailers, the optimal decision of cross-border e-commerce supply chain is as follows:

$$
\begin{aligned}
& \theta_{r}^{R *}=\frac{1}{3}, \\
& w^{R *}=\frac{8(a+c-a \rho) K_{2}-3(a+2 c) \lambda^{2}}{8(2-\rho) K_{2}-9 \lambda^{2}}, \\
& p^{R *}=\frac{4[c+a(3-2 \rho)] K_{2}-3(a+2 c) \lambda^{2}}{8(2-\rho) K_{2}-9 \lambda^{2}}, \\
& \theta_{2}^{R *}=\frac{6(a-c) \lambda}{8(2-\rho) K_{2}-9 \lambda^{2}} .
\end{aligned}
$$

Proof. Proof. The reverse induction method is used to solve the problem.

Firstly, determine the $\pi_{r}^{R}$ Hessian matrix for the domestic retailer profit function:

$$
\begin{aligned}
H\left(p, \theta_{2}\right) & =\left[\begin{array}{cc}
\frac{\partial^{2} \pi_{r}^{R}}{\partial\left(P^{R}\right)^{2}} & \frac{\partial^{2} \pi_{r}^{R}}{\partial P^{R} \partial \theta_{2}^{R}} \\
\frac{\partial^{2} \pi_{r}^{R}}{\partial \theta_{2}^{R} \partial P^{R}} & \frac{\partial^{2} \pi_{r}^{R}}{\partial\left(\theta_{2}^{R}\right)^{2}}
\end{array}\right] \\
= & {\left[\begin{array}{cc}
-2\left(1-\rho \theta_{m}\right) & \lambda\left(1-\rho \theta_{m}\right) \\
\lambda\left(1-\rho \theta_{m}\right) & -K_{2}+2 \lambda^{2} \rho \theta_{m}
\end{array}\right] . }
\end{aligned}
$$

It is not difficult to see from the above Hessian matrix, $\left(\partial^{2} \pi_{r}^{R} / \partial\left(P^{R}\right)^{2}\right)=-2\left(1-\rho \theta_{m}\right)<0$ and $|H|=2 K_{2}\left(1-\rho \theta_{m}\right)-$ $\lambda^{2}>0 ; \pi_{r}^{R}$ is a strictly joint concave function about $P^{R}$ and $\theta_{2}^{R}$, and there is an optimal solution to maximize profits; thus, the first-order partial derivation condition is $\overline{p^{R}}=\left((a+w) K_{2}\left(1-\theta_{r}\right)-w \lambda^{2} / 2 K_{2}\left(1-\theta_{r}\right)-\lambda^{2}\right) \quad$ and $\overline{\theta_{2}^{R}}=\left((a-w) \lambda / 2 K_{2}\left(1-\theta_{r}\right)-\lambda^{2}\right)$. Substituting $\overline{p^{R}}$ and $\overline{\theta_{2}^{R}}$ into formula (2), the second-order derivative function of profit function of overseas suppliers can be obtained. When $0<\rho<\left(4 K_{2}\left(1-\theta_{r}\right)^{2}-\lambda^{2}\left(2-3 \theta_{r}\right) / 2 K_{2}\left(1-\theta_{r}\right)^{2}\right), \quad\left(\partial^{2} \pi_{m}^{R} /\right.$ $\left.\partial\left(w^{R}\right)^{2}\right)=-\left(K_{2}\left[2(2-\rho) K_{2}\left(1-\theta_{r}\right)^{2}-\lambda^{2}\left(2-3 \theta_{r}\right)\right] / \quad\left[2 K_{2}\right.\right.$ $\left.\left.\left(1-\theta_{r}\right)-\lambda^{2}\right]^{2}\right)<0$.

It can be seen that $\pi_{m}^{M}$ is the strict concave function about $w^{M}$, and there is an optimal solution to maximize profits. Therefore, the first-order partial derivative condition is $w^{R}\left(\theta_{r}\right)=\left(2(a+c-a \rho) K_{2}\left(1-\theta_{r}\right)^{2}-\lambda^{2}[a+c-(2 a+c)\right.$ $\left.\left.\theta_{r}\right] / 2(2-\rho) K_{2}\left(1-\theta_{r}\right)^{2}-\lambda^{2}\left(2-3 \theta_{r}\right)\right)$, decisions of domestic retailers are $p^{R}\left(\theta_{r}\right)$ and $\theta_{2}^{R}\left(\theta_{r}\right)$, and profits from overseas suppliers at this time are $\pi_{m}^{R}\left(\theta_{r}\right)=\left((a-c)^{2} K_{2}\left(1-\theta_{r}\right)^{2} /\right.$ $\left.2\left[2(2-\rho) K_{2}\left(1-\theta_{r}\right)^{2}-\lambda^{2}\left(2-3 \theta_{r}\right)\right]\right)$.

According to $\left(\partial^{2} \pi_{m}^{R}\left(\theta_{r}\right) / \partial\left(\theta_{r}\right)^{2}\right)<0, \pi_{r}^{R}$ is the strict concave function about $\theta_{r}$, and there is an optimal solution to maximize the profits of overseas suppliers, so the firstorder partial derivative condition is $\theta_{r}^{R *}=(1 / 3)$.

Substituting $\theta_{r}^{R *}$ into formula $w^{R}\left(\theta_{r}\right), p^{R}\left(\theta_{r}\right)$, and $\theta_{2}^{R}\left(\theta_{r}\right)$, respectively, optimal decision-making available for overseas suppliers and domestic retailers can be obtained as $w^{R *}, p^{R *}$, and $\theta_{2}^{R *}$.

Finally, the market demand for commodities and the profits of members of cross-border e-commerce supply chains are

$$
\begin{aligned}
d^{R *} & =\frac{4(a-c) K_{2}}{8(2-\rho) K_{2}-9 \lambda^{2}}, \\
\pi_{m}^{R *} & =\frac{2(a-c)^{2} K_{2}}{8(2-\rho) K_{2}-9 \lambda^{2}}, \\
\pi_{r}^{R *} & =\frac{4(a-c)^{2} K_{2}\left(4 K_{2}-3 \lambda^{2}\right)}{\left[8(2-\rho) K_{2}-9 \lambda^{2}\right]^{2}} .
\end{aligned}
$$

In the semi-cooperative mode of supplier sharing retailer's propaganda cost, foreign suppliers are mostly willing to share $1 / 3$ propaganda cost of domestic retailers in order to maximize their profits.

3.4. Decision-Making under the Two-Way Cooperation Mode in Which Retailers Share Transportation Costs and Suppliers Share Publicity Costs (MR). The domestic retailers in this mode share the transportation costs of overseas suppliers in proportion of $\theta_{m}\left(0 \leq \theta_{m} \leq 1\right)$ based on their own profit maximization considerations, and the overseas suppliers share the propaganda costs of domestic retailers in proportion of $\theta_{r}\left(0 \leq \theta_{r} \leq 1\right)$ based on their own profit maximization considerations.

Under established condition $\theta_{m}$ and $\theta_{r}$, overseas suppliers will first determine wholesale prices, and then, domestic retailers determine retail prices $P^{\mathrm{MR}}$ and publicity strategies $\theta_{2}^{\mathrm{MR}}$.

Under this condition, the profit of overseas suppliers and domestic retailers under the cooperation mode is 


$$
\begin{aligned}
& \pi_{m}^{\mathrm{MR} *}=\left\{w-\left(1-\theta_{m}\right)\left[c-\rho\left(a-p+\lambda \theta_{2}\right)\right]\right\}\left(a-p+\lambda \theta_{2}\right)-\frac{1}{2} \theta_{r} K_{2} \theta_{2}^{2}, \\
& \pi_{r}^{\mathrm{MR} *}=\left\{p-w-\theta_{m}\left[c-\rho\left(a-p+\lambda \theta_{2}\right)\right]\right\}\left(a-p+\lambda \theta_{2}\right)-\frac{1}{2}\left(1-\theta_{r}\right) K_{2} \theta_{2}^{2} .
\end{aligned}
$$

Proposition 4. Under the two-way cooperation mode between overseas suppliers and domestic retailers, the optimal decision of cross-border e-commerce supply chain is

$$
\begin{aligned}
& \theta_{m}^{\mathrm{MR} *}=\left(1-\frac{3 \lambda^{2}}{8 \rho K_{2}}\right), \\
& \theta_{r}^{\mathrm{MR} *}=\frac{1}{3}, \\
& w^{\mathrm{MR} *}=\frac{4(a-c) \rho K_{2}+3 c \lambda^{2}}{8 \rho K_{2}}, \\
& p^{\mathrm{MR} *}=\frac{2[c+a(3-4 \rho)] K_{2}-3 c \lambda^{2}}{8(1-\rho) K_{2}-3 \lambda^{2}}, \\
& \theta_{2}^{\mathrm{MR} *}=\frac{3(a-c) \lambda}{8(1-\rho) K_{2}-3 \lambda^{2}} .
\end{aligned}
$$

Proof. The reverse induction method is used to solve the problem.

Firstly, determine the $\pi_{r}^{\mathrm{MR}}$ Hessian matrix for the domestic retailer profit function:

$$
\begin{aligned}
H\left(p, \theta_{2}\right) & =\left[\begin{array}{cc}
\frac{\partial^{2} \pi_{r}^{\mathrm{MR}}}{\partial\left(P^{\mathrm{MR}}\right)^{2}} & \frac{\partial^{2} \pi_{r}^{\mathrm{MR}}}{\partial P^{\mathrm{MR}} \partial \theta_{2}^{\mathrm{MR}}} \\
\frac{\partial^{2} \pi_{r}^{\mathrm{MR}}}{\partial \theta_{2}^{\mathrm{MR}} \partial P^{\mathrm{MR}}} & \frac{\partial^{2} \pi_{r}^{\mathrm{MR}}}{\partial\left(\theta_{2}^{\mathrm{MR}}\right)^{2}}
\end{array}\right] \\
= & {\left[\begin{array}{cc}
-2\left(1-\rho \theta_{m}\right) & \lambda\left(1-\rho \theta_{m}\right) \\
\lambda\left(1-\rho \theta_{m}\right) & -K_{2}+2 \lambda^{2} \rho \theta_{m}
\end{array}\right] . }
\end{aligned}
$$

It is not difficult to see from the above Hessian matrix: $\left(\partial^{2} \pi_{r}^{\mathrm{MR}} / \partial\left(P^{\mathrm{MR}}\right)^{2}\right)=-2\left(1-\rho \theta_{m}\right)<0$ and $|H|=2 K_{2}(1-$ $\left.\rho \theta_{m}\right)\left(1-\theta_{r}\right)-\lambda^{2}>0$. Thus, $\pi_{r}^{R}$ is a strictly joint concave function about $P^{R}$ and $\theta_{2}^{R}$, and there is an optimal solution to maximize profits.

Secondly, first-order partial derivation conditions are as follows:

$$
\begin{aligned}
\overline{p^{\mathrm{MR}}} & =\frac{K_{2}\left[a+w+(c-2 a \rho) \theta_{m}\right]\left(1-\theta_{r}\right)-\lambda^{2}\left(w+c \theta_{m}\right)}{2 K_{2}\left(1-\rho \theta_{m}\right)\left(1-\theta_{r}\right)-\lambda^{2}}, \\
\overline{\theta_{2}^{\mathrm{MR}}} & =\frac{\lambda\left(a-w-c \theta_{m}\right)}{2 K_{2}\left(1-\rho \theta_{m}\right)\left(1-\theta_{r}\right)-\lambda^{2}} .
\end{aligned}
$$

Substituting $\overline{p^{\mathrm{MR}}}$ and $\overline{\theta_{2}^{\mathrm{MR}}}$ into formula (7), the secondorder derivative of the profit function of overseas suppliers can be obtained.

$$
\begin{aligned}
& \text { When } \quad 0<\rho<\left(4 K_{2}\left(1-\theta_{r}\right)^{2}-\lambda^{2}\left(2-3 \theta_{r}\right) / 2 K_{2}(1+\right. \\
& \left.\left.\theta_{m}\right)\left(1-\theta_{r}\right)^{2}\right), \\
& \frac{\partial^{2} \pi_{m}^{R}}{\partial\left(w^{R}\right)^{2}}=-\frac{K_{2}\left\{2 K_{2}\left[2-\rho\left(1+\theta_{m}\right)\right]\left(1-\theta_{r}\right)^{2}-\lambda^{2}\left(2-3 \theta_{r}\right)\right\}}{\left[2 K_{2}\left(1-\rho \theta_{m}\right)\left(1-\theta_{r}\right)-\lambda^{2}\right]^{2}}<0 .
\end{aligned}
$$

It can be seen that $\pi_{m}^{\mathrm{MR}}$ is the strict concave function about $w^{\mathrm{MR}}$, and there is an optimal solution to maximize profits. Therefore, the first-order partial derivative condition is $w^{\mathrm{MR}}\left(\theta_{m}, \theta_{r}\right)=\left(2 K_{2}\left[a(1-\rho)+c\left(1-2 \theta_{m}+\right.\right.\right.$ $\left.\left.\rho \theta_{m}^{2}\right)\right]\left(1-\theta_{r}\right)^{2}-\lambda^{2}\left[a+c-c \theta_{m}\left(2-3 \theta_{r}\right)-(2 a+c) \theta_{r}\right] / 2 K_{2}$ $\left.\left[2-\rho\left(1+\theta_{m}\right)\right]\left(1-\theta_{r}\right)^{2}-\lambda^{2}\left(2-3 \theta_{r}\right)\right)$, so decision-making by domestic retailers is $p^{\mathrm{MR}}\left(\theta_{m}, \theta_{r}\right)$ and $\theta_{2}^{\mathrm{MR}}\left(\theta_{m}, \theta_{r}\right)$.

At this point, the profits of the cross-border e-commerce supply chain are

$$
\begin{aligned}
& \pi_{m}^{\mathrm{MR}}\left(\theta_{m}, \theta_{r}\right)=\frac{(a-c)^{2} K_{2}\left(1-\theta_{r}\right)^{2}}{2\left(2 K_{2}\left(2-\rho\left(1+\theta_{m}\right)\right)\left(1-\theta_{r}\right)^{2}-\lambda^{2}\left(2-3 \theta_{r}\right)\right)}, \\
& \pi_{r}^{\mathrm{MR}}\left(\theta_{m}, \theta_{r}\right)=\frac{(a-c)^{2} K_{2}\left[2 K_{2}\left(1-\rho \theta_{m}\right)\left(1-\theta_{r}\right)-\lambda^{2}\right]\left(1-\theta_{r}\right)^{3}}{2\left\{2 K_{2}\left[2-\rho\left(1+\theta_{m}\right)\right]\left(1-\theta_{r}\right)^{2}-\lambda^{2}\left(2-3 \theta_{r}\right)\right\}^{2}} .
\end{aligned}
$$

According to $\left(\partial \pi_{r}^{\mathrm{MR}}\left(\theta_{m}, \theta_{r}\right) / \partial \theta_{m}\right)=0 \quad$ and $\left(\partial \pi_{m}^{\mathrm{MR}}\left(\theta_{m}, \theta_{r}\right) / \partial \theta_{r}\right)=0$, the optimal proportion of overseas suppliers and domestic retailers sharing each other's corresponding costs, under this cooperation mode, is $\left\{\begin{array}{l}\theta_{m}^{\mathrm{MR} *}=1-\left(3 \lambda^{2} / 8 \rho K_{2}\right) \\ \theta_{r}^{\mathrm{MR} *}=(1 / 3)\end{array}\right.$.

Substituting $\theta_{m}^{\mathrm{MR} *}$ and $\theta_{r}^{\mathrm{MR} *}$ into $w^{\mathrm{MR}}\left(\theta_{m}, \theta_{r}\right)$, $p^{\mathrm{MR}}\left(\theta_{m}, \theta_{r}\right)$, and $\theta_{2}^{\mathrm{MR}}\left(\theta_{m}, \theta_{r}\right)$, respectively, optimal decisions for overseas suppliers and domestic retailers can be obtained as $w^{\mathrm{MR} *}, p^{\mathrm{MR} *}$, and $\theta_{2}^{\mathrm{MR} *}$.

Finally, it can be determined that the commodity market demand and the profits of the members of the cross-border e-commerce supply chain are as follows:

$$
\begin{aligned}
d^{\mathrm{MR} *} & =\frac{2(a-c) K_{2}}{8(1-\rho) K_{2}-3 \lambda^{2}}, \\
\pi_{m}^{\mathrm{MR} *} & =\frac{(a-c)^{2} K_{2}}{8(1-\rho) K_{2}-3 \lambda^{2}}, \\
\pi_{r}^{\mathrm{MR} *} & =\frac{(a-c)^{2} K_{2}}{2\left(8(1-\rho) K_{2}-3 \lambda^{2}\right)} .
\end{aligned}
$$


Under the two-way cooperation mode between overseas suppliers and domestic retailers, retailers are no longer willing to share the total transportation costs of suppliers, but suppliers are still willing to share one-third of the promotional costs of retailers.

\section{Comparative Analysis}

Proposition 5. Under the specific unit transportation cost, the pricing decisions of different cooperation modes satisfy the following:

$$
\begin{gathered}
w^{R *}>w^{N *}>w^{\mathrm{MR} *}>w^{M *}, \\
p^{R *}>p^{N *}>p^{\mathrm{MR} *}>p^{M *} .
\end{gathered}
$$

Proof. According to the above proposition, comparing the optimal solutions under the four different cooperation modes, the following relationships can be found:

$$
\begin{aligned}
& w^{R *}-w^{N *}=\frac{(a-c) \lambda^{2}\left[(6-4 \rho) K_{2}-3 \lambda^{2}\right]}{2\left[(2-\rho) K_{2}-\lambda^{2}\right]\left[8(2-\rho) K_{2}-9 \lambda^{2}\right]}>0, \\
& w^{N *}-w^{M R *}=\frac{4 \rho[4 c-(c+a) \rho] K_{2}^{2}-c \lambda^{2}(6+5 \rho) K_{2}+3 c \lambda^{4}}{8 \rho K_{2}\left[(2-\rho) K_{2}-\lambda^{2}\right]}>0, \\
& w^{M R *}-w^{M *}=\frac{3 c \lambda^{2}}{8 \rho K_{2}}>0 \\
& p^{R *}-p^{N *}=\frac{(a-c) \lambda^{2}\left[(7-4 \rho) K_{2}-3 \lambda^{2}\right]}{2\left[(2-\rho) K_{2}-\lambda^{2}\right]\left[8(2-\rho) K_{2}-9 \lambda^{2}\right]}>0, \\
& p^{N *}-p^{M R *}=\frac{(a-c)\left[4 \rho K_{2}^{2}-\lambda^{2}(5+2 \rho) K_{2}+3 \lambda^{4}\right]}{2\left[(2-\rho) K_{2}-\lambda^{2}\right]\left[8(1-\rho) K_{2}-3 \lambda^{2}\right]}>0, \\
& p^{M R *}-p^{M *}=\frac{(a-c) \lambda^{2}\left[(5-4 \rho) K_{2}-3 \lambda^{2}\right]}{2\left[2(1-\rho) K_{2}-\lambda^{2}\right]\left[8(1-\rho) K_{2}-3 \lambda^{2}\right]}>0 . \\
& \theta_{2}^{\mathrm{MR} *}-\theta_{2}^{R *}=\frac{3(a-c) \lambda\left(8 \rho K_{2}-3 \lambda^{2}\right)}{\left[8(2-\rho) K_{2}-9 \lambda^{2}\right]\left[8(1-\rho) K_{2}-3 \lambda^{2}\right]}>0, \\
& \theta_{2}^{\mathrm{MR} *}-\theta_{2}^{M *}=\frac{(a-c) \lambda\left[4(1-\rho) K_{2}-3 \lambda^{2}\right]}{2\left[2(1-\rho) K_{2}-\lambda^{2}\right]\left[8(1-\rho) K_{2}-3 \lambda^{2}\right]}>0 \text {, } \\
& \theta_{2}^{R *}-\theta_{2}^{M *}=\frac{(a-c) \lambda\left[8(1-2 \rho) K_{2}-3 \lambda^{2}\right]}{2\left[8(2-\rho) K_{2}-9 \lambda^{2}\right]\left[2(1-\rho) K_{2}-\lambda^{2}\right]} \text {. }
\end{aligned}
$$

It is found from Proposition 5 that, when overseas suppliers share part of the publicity costs of domestic retailers, the premise of raising or lowering wholesale prices is that domestic retailers are willing to share all or part of their transportation costs. Also, the retail price ranking of domestic retailers is consistent with the wholesale price ranking of overseas suppliers. More importantly, in the pricing decision of cross-border e-commerce supply chain, the cost of upstream enterprises will be transferred directly to downstream enterprises and eventually apportioned to each consumer.

Proposition 6. Under the specific unit transportation cost, the propaganda strategy of different cooperation modes satisfies the following:

When $0<\rho<\left(8 K_{2}-3 \lambda^{2} / 16 K_{2}\right), \theta_{2}^{M R}>\theta_{2}^{R}>\theta_{2}^{M}>\theta_{2}^{N}$.

When $\left(8 K_{2}-3 \lambda^{2} / 16 K_{2}\right)<\rho<1, \theta_{2}^{M R}>\theta_{2}^{M}>\theta_{2}^{R}>\theta_{2}^{N}$.

Proof. According to the above proposition, comparing the optimal solutions under the four different cooperation modes, the following relationships can be found:
When $0<\rho<\left(8 K_{2}-3 \lambda^{2} / 16 K_{2}\right)\left((a-c) \lambda\left(8(1-2 \rho) K_{2}-\right.\right.$ $\left.\left.3 \lambda^{2}\right) / 2\left[8 \quad(2-\rho) K_{2}-9 \lambda^{2}\right]\left[2(1-\rho) K_{2}-\lambda^{2}\right]\right)>0$, i.e., $\theta_{2}^{R *}>\theta_{2}^{M *}$.

When $\left(8 K_{2}-3 \lambda^{2} / 16 K_{2}\right)<\rho<1,\left((a-c) \lambda\left(8(1-2 \rho) K_{2}-\right.\right.$ $\left.\left.3 \lambda^{2}\right) / 2\left[8(2-\rho) K_{2}-9 \lambda^{2}\right]\left[2(1-\rho) K_{2}-\lambda^{2}\right]\right)<0$, i.e., $\theta_{2}^{R *}<$ $\theta_{2}^{M *} ; \quad \theta_{2}^{R *}-\theta_{2}^{N *}=\left((a-c) \lambda\left[4(2-\quad \rho) K_{2}-3 \lambda^{2}\right] / \quad 2[(2-\right.$ $\left.\left.\rho) K_{2}-\lambda^{2}\right]\left[8(2-\rho) K_{2}-9 \lambda^{2}\right]\right)>0$, and $\theta_{2}^{M *}-\theta_{2}^{N *}=((a-$ c) $\left.\lambda \rho K_{2} / 2\left[(2-\rho) K_{2}-\lambda^{2}\right]\left[2(1-\rho) K_{2}-\lambda^{2}\right]\right)>0$.

It is found from Proposition 6 that the two-way cooperation mode between overseas suppliers and domestic retailers can most effectively enhance the product publicity strategy of domestic retailers. However, for the two one-way 
cooperation modes, with the increase in unit transportation cost, the initial one-way cooperation of the supplier sharing the retailer's propaganda cost will become the one-way cooperation of the retailer sharing the supplier's transportation cost.

Proposition 7. Under the specific unit transportation cost, the profits of cross-border e-commerce supply chain members of different cooperation modes satisfy, respectively, the following:

$$
\begin{array}{r}
\pi_{m}^{M *}>\pi_{m}^{\mathrm{MR} *}>\pi_{m}^{R *}>\pi_{m}^{N *}, \\
\pi_{r}^{M}>\pi_{r}^{\mathrm{MR}}>\pi_{r}^{N}>\pi_{r}^{R} .
\end{array}
$$

Proof. According to the above proposition, comparing the profits of cross-border e-commerce supply chain members under four different cooperation modes, we can get the following relationship:

$$
\begin{aligned}
\pi_{m}^{M *}-\pi_{m}^{\mathrm{MR} *} & =\frac{(a-c)^{2} \lambda^{2} K_{2}}{4\left[2(1-\rho) K_{2}-\lambda^{2}\right]\left[8(1-\rho) K_{2}-3 \lambda^{2}\right]}>0, \\
\pi_{m}^{\mathrm{MR} *}-\pi_{m}^{R *} & =\frac{(a-c)^{2} K_{2}\left(8 \rho K_{2}-3 \lambda^{2}\right)}{\left[8(2-\rho) K_{2}-9 \lambda^{2}\right]\left[8(1-\rho) K_{2}-3 \lambda^{2}\right]}>0, \\
\pi_{m}^{R *}-\pi_{m}^{N *} & =\frac{(a-c)^{2} \lambda^{2} K_{2}}{4\left[(2-\rho) K_{2}-\lambda^{2}\right]\left[8(2-\rho) K_{2}-9 \lambda^{2}\right]}>0, \\
\pi_{r}^{M *}-\pi_{r}^{\mathrm{MR} *} & =\frac{(a-c)^{2} \lambda^{2} K_{2}}{8\left[2(1-\rho) K_{2}-\lambda^{2}\right]\left[8(1-\rho) K_{2}-3 \lambda^{2}\right]}>0, \\
\pi_{r}^{\mathrm{MR} *}-\pi_{r}^{N *} & =\frac{(a-c)^{2} K_{2}\left(4 \rho^{2} K_{2}^{2}-2 \lambda^{2} K_{2}+\lambda^{4}\right)}{8\left[(2-\rho) K_{2}-\lambda^{2}\right]^{2}\left[8(1-\rho) K_{2}-3 \lambda^{2}\right]}>0, \\
\pi_{r}^{N *}-\pi_{r}^{R *} & =\frac{(a-c)^{2} \lambda^{2} K_{2}\left[32\left(2-3 \rho+\rho^{2}\right] K_{2}^{2}-2 \lambda^{2}[31-24 \rho) K_{2}+15 \lambda^{4}\right]}{8\left[(2-\rho) K_{2}-\lambda^{2}\right]^{2}\left[8(2-\rho) K_{2}-9 \lambda^{2}\right]^{2}}>0 .
\end{aligned}
$$

It is found from Proposition 7 that both overseas suppliers and domestic retailers will choose the one-way cooperation mode of retailers sharing the transportation costs of suppliers and the two-way cooperation mode to improve their profits, and the former is more effective than the latter.

\section{Coordination Analysis}

In cross-border e-commerce, even if overseas suppliers and domestic retailers choose the decision-making mode of semi-cooperation (between non-cooperation and full cooperation), the two parties will still keep some room for profit. Therefore, it is necessary to introduce the Shapley value method and full cooperative decision profit incremental sharing mechanism to coordinate non-cooperation and the three semi-cooperation modes, but before that, it is necessary to analyze the problem of full cooperative decision-making between suppliers and retailers.

5.1. Coordination of the Full Cooperation Mode between Overseas Suppliers and Domestic Retailer (C). In the mode of full cooperation, the members of the supply chain of cross-border e-commerce pay great attention to the maximization of the overall benefit, so they generally make joint decisions on the retail price $P^{C}$ and propaganda strategy $\theta_{2}^{C}$ of the goods at the same time.

Therefore, the profit of cross-border e-commerce supply chain under the mode of full cooperation is as follows:

$$
\pi_{\mathrm{sc}}^{C}=(p-c)\left(a-p+\lambda \theta_{2}\right)+\rho\left(a-p+\lambda \theta_{2}\right)^{2}-\frac{1}{2} K_{2} \theta_{2}^{2} .
$$

Proposition 8. Under the mode of full cooperation between overseas suppliers and domestic retailers, the optimal decision of cross-border e-commerce supply chain is

$$
\begin{aligned}
p^{C *} & =\frac{(a+c-2 a \rho) K_{2}-c \lambda^{2}}{2(1-\rho) K_{2}-\lambda^{2}}, \\
\theta_{2}^{C *} & =\frac{(a-c) \lambda}{2(1-\rho) K_{2}-\lambda^{2}} .
\end{aligned}
$$

Proof. Solved by reverse induction. 
Firstly, determine Hessian matrix of $\pi_{\mathrm{sc}}^{C}$ for the domestic retailer profit function:

$$
H\left(p, \theta_{2}\right)=\left[\begin{array}{ll}
\frac{\partial^{2} \pi_{s c}^{C}}{\partial\left(P^{C}\right)^{2}} & \frac{\partial^{2} \pi_{s c}^{C}}{\partial P^{C} \partial \theta_{2}^{C}} \\
\frac{\partial^{2} \pi_{s c}^{C}}{\partial \theta_{2}^{C} \partial P^{C}} & \frac{\partial^{2} \pi_{s c}^{C}}{\partial\left(\theta_{2}^{C}\right)^{2}}
\end{array}\right]=\left[\begin{array}{cc}
-2(1-\rho) & \lambda(1-2 \rho) \\
\lambda(1-2 \rho) & -K_{2}+2 \lambda^{2} \rho
\end{array}\right] .
$$

It is not difficult to see from the above Hessian matrix: when $0<\rho<\left(2 K_{2}-\lambda^{2} / 2 K_{2}\right), \quad\left(\partial^{2} \pi_{r}^{\mathrm{MR}} / \partial\left(P^{\mathrm{MR}}\right)^{2}\right)=-2(1-$ $\rho)<0$ and $|H|=2(1-\rho) K_{2}-\lambda^{2}>0$. Thus, $\pi_{\mathrm{sc}}^{\mathrm{C}}$ is a strictly joint concave function about $P^{C}$ and $\theta_{2}^{C}$, and there is an optimal solution to maximize profits. So the first-order partial derivation conditions are as follows: $p^{C *}=\left((a+c-2 a \rho) K_{2}-\right.$ $\left.c \lambda^{2} / 2(1-\rho) K_{2}-\lambda^{2}\right)$ and $\theta_{2}^{C *}=\left((a-c) \lambda / 2(1-\rho) K_{2}-\lambda^{2}\right)$, and the market demand for commodities and the profits of cross-border e-commerce supply chain can be determined as

$$
\begin{aligned}
& d^{C *}=\frac{(a-c) K_{2}}{2(1-\rho) K_{2}-\lambda^{2}}, \\
& \pi_{\mathrm{sc}}^{\mathrm{C}}=\frac{(a-c)^{2} K_{2}}{2\left[2(1-\rho) K_{2}-\lambda^{2}\right]} .
\end{aligned}
$$

5.2. Shapley Value Method Coordination (S). Shapley value method is a method of fair distribution of cooperative income based on the marginal contribution of individuals to the whole.

For the non-cooperation mode and 3 semi-cooperation modes between overseas suppliers and domestic retailers, the Shapley value method is used to distribute the overall supply chain profits when the two fully cooperate, and the profits distributed by both sides under different cooperation modes can be obtained:

(1) Non-cooperative coordination between overseas suppliers and domestic retailers (SN)

At this point,

$$
\begin{aligned}
& \pi_{m}^{\mathrm{SN} *}=\frac{1}{2} \pi_{m}^{N *}+\frac{1}{2}\left(\pi_{\mathrm{sc}}^{\mathrm{C} *}-\pi_{r}^{N *}\right)=\frac{(a-c)^{2} K_{2}}{4\left[2(1-\rho) K_{2}-\lambda^{2}\right]}+\frac{(a-c)^{2} K_{2}\left[2(1-\rho) K_{2}-\lambda^{2}\right]}{16\left[(2-\rho) K_{2}-\lambda^{2}\right]^{2}}, \\
& \pi_{r}^{\mathrm{SN} *}=\frac{1}{2} \pi_{r}^{N *}+\frac{1}{2}\left(\pi_{\mathrm{sc}}^{\mathrm{C} *}-\pi_{m}^{N *}\right)=\frac{(a-c)^{2} K_{2}}{4\left[2(1-\rho) K_{2}-\lambda^{2}\right]}-\frac{(a-c)^{2} K_{2}\left[2(1-\rho) K_{2}-\lambda^{2}\right]}{16\left[(2-\rho) K_{2}-\lambda^{2}\right]^{2}} .
\end{aligned}
$$

(2) One-way cooperative coordination of domestic retailers sharing transportation costs for overseas suppliers (SM)

At this point,

$$
\begin{aligned}
& \pi_{m}^{\mathrm{SM} *}=\frac{1}{2} \pi_{m}^{M *}+\frac{1}{2}\left(\pi_{\mathrm{sc}}^{\mathrm{C} *}-\pi_{r}^{M *}\right)=\frac{5(a-c)^{2} K_{2}}{16\left[2(1-\rho) K_{2}-\lambda^{2}\right]}, \\
& \pi_{r}^{\mathrm{SM} *}=\frac{1}{2} \pi_{r}^{M *}+\frac{1}{2}\left(\pi_{\mathrm{sc}}^{\mathrm{C} *}-\pi_{m}^{M *}\right)=\frac{3(a-c)^{2} K_{2}}{16\left[2(1-\rho) K_{2}-\lambda^{2}\right]} .
\end{aligned}
$$

(3) One-way cooperative coordination of domestic retailers sharing publicity costs for overseas suppliers (SR)

At this point,

$$
\begin{aligned}
& \pi_{m}^{\mathrm{SR} *}=\frac{1}{2} \pi_{m}^{R *}+\frac{1}{2}\left(\pi_{\mathrm{sc}}^{\mathrm{C} *}-\pi_{r}^{R *}\right)=\frac{(a-c)^{2} K_{2}}{4\left[2(1-\rho) K_{2}-\lambda^{2}\right]}+\frac{(a-c)^{2} K_{2}\left[8(1-\rho) K_{2}-3 \lambda^{2}\right]}{\left[8(2-\rho) K_{2}-9 \lambda^{2}\right]^{2}}, \\
& \pi_{r}^{\mathrm{SR} *}=\frac{1}{2} \pi_{r}^{R *}+\frac{1}{2}\left(\pi_{\mathrm{sc}}^{\mathrm{C} *}-\pi_{m}^{R *}\right)=\frac{(a-c)^{2} K_{2}}{4\left[2(1-\rho) K_{2}-\lambda^{2}\right]}-\frac{(a-c)^{2} K_{2}\left[8(1-\rho) K_{2}-3 \lambda^{2}\right]}{\left[8(2-\rho) K_{2}-9 \lambda^{2}\right]^{2}} .
\end{aligned}
$$

(4) Two-way cooperative coordination of domestic retailers sharing transportation costs of overseas suppliers and overseas suppliers sharing promotional costs of domestic retailers (SMR) 
At this point,

$$
\begin{aligned}
& \pi_{m}^{\mathrm{SMR} *}=\frac{1}{2} \pi_{m}^{\mathrm{MR} *}+\frac{1}{2}\left(\pi_{\mathrm{sc}}^{\mathrm{C} *}-\pi_{r}^{\mathrm{MR} *}\right)=\frac{(a-c)^{2} K_{2}}{4\left(2(1-\rho) K_{2}-\lambda^{2}\right)}+\frac{(a-c)^{2} K_{2}}{4\left(8(1-\rho) K_{2}-3 \lambda^{2}\right)}, \\
& \pi_{r}^{\mathrm{SMR} *}=\frac{1}{2} \pi_{r}^{\mathrm{MR} *}+\frac{1}{2}\left(\pi_{\mathrm{sc}}^{\mathrm{C} *}-\pi_{m}^{\mathrm{MR} *}\right)=\frac{(a-c)^{2} K_{2}}{4\left(2(1-\rho) K_{2}-\lambda^{2}\right)}-\frac{(a-c)^{2} K_{2}}{4\left(8(1-\rho) K_{2}-3 \lambda^{2}\right)} . \\
& T_{m}=c\left(a-p+\lambda \theta_{2}\right), \\
& \text { Suppliers and Retailers }(V) \text {. The profit } \\
& \text { of the shared system is based on the }
\end{aligned}
$$

5.3. Benefit-Sharing Coordination for Full Cooperation Decision-Making between Suppliers and Retailers $(V)$. The profit increment mechanism of the shared system is based on the profit increment of the whole supply chain under the decision of full cooperation, compared with that under the decision of non-cooperation or semi-cooperation. The system income increment is distributed to each member according to the proportion of the supply chain member's input.

Therefore, the input of overseas suppliers and domestic retailers is as follows, respectively:
5.3.1. Non-Cooperative Coordination between Suppliers and Retailers (VN). Under this structure, the income increment of supply chain is as follows:

$$
\Delta \pi^{\mathrm{VN}}=\pi_{\mathrm{sc}}^{C *}-\left(\pi_{m}^{N *}+\pi_{r}^{N *}\right)=\frac{(a-c)^{2}\left(2 K_{2}-\lambda^{2}\right)^{2} K_{2}}{8\left[(2-\rho) K_{2}-\lambda^{2}\right]^{2}\left[2(1-\rho) K_{2}-\lambda^{2}\right]} .
$$

Substituting the aforementioned values of $P^{N *}, \theta_{2}^{N *}$ into (47) and (48), the proportion of input from overseas suppliers and domestic retailers to the total input of the supply chain is

$$
\begin{aligned}
& \theta_{m}^{\mathrm{VN} *}=\frac{T_{m}^{N}}{T_{m}^{N}+T_{r}^{N}}=\frac{4 c\left[(2-\rho) K_{2}-\lambda^{2}\right]}{4[c(3-\rho)+a(1-\rho)] K_{2}-(a+7 c) \lambda^{2}}, \\
& \theta_{r}^{\mathrm{VN} *}=\frac{T_{r}^{N}}{T_{m}^{N}+T_{r}^{N}}=\frac{4[a(1-\rho)+c] K_{2}-(a+3 c) \lambda^{2}}{4[c(3-\rho)+a(1-\rho)] K_{2}-(a+7 c) \lambda^{2}} .
\end{aligned}
$$

Thus, the profits of overseas suppliers and domestic retailers after coordination are

$$
\begin{aligned}
& \pi_{m}^{\mathrm{VN} *}=\frac{(a-c)^{2} K_{2}}{4\left[(2-\rho) K_{2}-\lambda^{2}\right]}+\theta_{m}^{\mathrm{VN} *}\left(\Delta \pi^{\mathrm{VN}}\right), \\
& \pi_{r}^{\mathrm{VN} *}=\frac{(a-c)^{2}\left(2 K_{2}-\lambda^{2}\right) K_{2}}{8\left[(2-\rho) K_{2}-\lambda^{2}\right]^{2}}+\theta_{r}^{\mathrm{VN} *}\left(\Delta \pi^{\mathrm{VN}}\right) .
\end{aligned}
$$

5.3.2. Coordination of One-Way Cooperation of Retailers Sharing Suppliers' Transport Costs (VM). In this mode, the income increment of supply chain system is as follows:

$$
\Delta \pi^{\mathrm{VM}}=\pi_{\mathrm{sc}}^{C *}-\left(\pi_{m}^{M *}+\pi_{r}^{M *}\right)=\frac{(a-c)^{2} K_{2}}{8\left[2(1-\rho) K_{2}-\lambda^{2}\right]}
$$

Substituting formulas (12) and (13) $P^{M *}, \theta_{2}^{M *}$ into (47) and (48), the proportion of input from overseas suppliers and domestic retailers to the total input of the supply chain is

$$
\begin{aligned}
\theta_{m}^{\mathrm{VM} *} & =\frac{T_{m}^{M}}{T_{m}^{M}+T_{r}^{M}}=\frac{4 c\left[2(1-\rho) K_{2}-\lambda^{2}\right]}{4(a+c)(1-\rho) K_{2}-(a+3 c) \lambda^{2}}, \\
\theta_{r}^{\mathrm{VM} *} & =\frac{T_{r}^{M}}{T_{m}^{M}+T_{r}^{M}}=\frac{(a-c)\left[4(1-\rho) K_{2}-\lambda^{2}\right]}{4(a+c)(1-\rho) K_{2}-(a+3 c) \lambda^{2}} .
\end{aligned}
$$

Thus, the profits of overseas suppliers and domestic retailers after coordination are as follows:

$$
\begin{aligned}
& \pi_{m}^{\mathrm{VM} *}=\frac{(a-c)^{2} K_{2}}{4\left[2(1-\rho) K_{2}-\lambda^{2}\right]}+\theta_{m}^{\mathrm{VM} *}\left(\Delta \pi^{\mathrm{VM}}\right), \\
& \pi_{r}^{\mathrm{VM} *}=\frac{(a-c)^{2} K_{2}}{8\left[2(1-\rho) K_{2}-\lambda^{2}\right]}+\theta_{r}^{\mathrm{VM} *}\left(\Delta \pi^{\mathrm{VM}}\right) .
\end{aligned}
$$


5.3.3. Coordination of One-Way Cooperation of Suppliers Sharing Retailers' Publicity Costs (VR). In this mode, the income increment of supply chain system is

$$
\Delta \pi^{\mathrm{VR}}=\pi_{\mathrm{sc}}^{C *}-\left(\pi_{m}^{R *}+\pi_{r}^{R *}\right)=\frac{(a-c)^{2} K_{2}\left[21 \lambda^{4}-8 \lambda^{2}(9+\rho) K_{2}+64 K_{2}^{2}\right]}{2\left[8(2-\rho) K_{2}-9 \lambda^{2}\right]^{2}\left[2(1-\rho) K_{2}-\lambda^{2}\right]} .
$$

Substituting formulas (19) and (20) $P^{R *}, \theta_{2}^{R *}$ into (47) and (48), the proportion of input from overseas suppliers and domestic retailers to the total input of the supply chain is

$$
\begin{aligned}
\theta_{m}^{\mathrm{VR} *} & =\frac{T_{m}^{R}}{T_{m}^{R}+T_{r}^{R}}=\frac{2 c\left[8(2-\rho) K_{2}-9 \lambda^{2}\right]}{3(a-13 c) \lambda^{2}+16[c(3-\rho)+a(1-\rho)] K_{2}}, \\
\theta_{r}^{\mathrm{VR} *} & =\frac{T_{r}^{R}}{T_{m}^{R}+T_{r}^{R}}=\frac{16[a(1-\rho)+c] K_{2}+3(a-7 c) \lambda^{2}}{3(a-13 c) \lambda^{2}+16[c(3-\rho)+a(1-\rho)] K_{2}} .
\end{aligned}
$$

Thus, the profits of overseas suppliers and domestic retailers after coordination are

$$
\begin{aligned}
& \pi_{m}^{\mathrm{VR} *}=\frac{2(a-c)^{2} K_{2}}{8(2-\rho) K_{2}-9 \lambda^{2}}+\theta_{m}^{\mathrm{VR} *}\left(\Delta \pi^{\mathrm{VR}}\right), \\
& \pi_{r}^{\mathrm{VR} *}=\frac{4(a-c)^{2} K_{2}\left(4 K_{2}-3 \lambda^{2}\right)}{\left[8(2-\rho) K_{2}-9 \lambda^{2}\right]^{2}}+\theta_{r}^{\mathrm{VR} *}\left(\Delta \pi^{\mathrm{VR}}\right) .
\end{aligned}
$$

5.3.4. Coordination of Two-Way Cooperation of Retailers Sharing Suppliers' Transport Costs and Suppliers Sharing Retailers' Publicity Costs (VMR). In this mode, the income increment of supply chain system is

$$
\Delta \pi^{\mathrm{VMR}}=\pi_{\mathrm{sc}}^{C *}-\left(\pi_{m}^{\mathrm{MR} *}+\pi_{r}^{\mathrm{MR} *}\right)=\frac{(a-c)^{2}(1-\rho) K_{2}^{2}}{\left[2(1-\rho) K_{2}-\lambda^{2}\right]\left[8(1-\rho) K_{2}-3 \lambda^{2}\right]} .
$$

Substituting formulas (27) and (28) $P^{\mathrm{MR} *}, \theta_{2}^{\mathrm{MR} *}$ into (47) and (49), the proportion of input from overseas suppliers and domestic retailers to the total input of the supply chain is

$$
\begin{aligned}
& \theta_{m}^{\mathrm{VMR} *}=\frac{T_{m}^{\mathrm{MR}}}{T_{m}^{\mathrm{MR}}+T_{r}^{\mathrm{MR}}}=\frac{8 c \rho K_{2}\left[8(1-\rho) K_{2}-3 \lambda^{2}\right]}{32(a+c)(1-\rho) \rho K_{2}^{2}+6 \lambda^{2}[c(4-9 \rho)+a \rho] K_{2}-9 c \lambda^{4}}, \\
& \theta_{r}^{\mathrm{VMR} *}=\frac{T_{r}^{\mathrm{MR}}}{T_{m}^{\mathrm{MR}}+T_{r}^{\mathrm{MR}}}=\frac{32(a-c)(1-\rho) \rho K_{2}^{2}+6 \lambda^{2}[c(4-5 \rho)+a \rho] K_{2}-9 c \lambda^{4}}{32(a+c)(1-\rho) \rho K_{2}^{2}+6 \lambda^{2}[c(4-9 \rho)+a \rho] K_{2}-9 c \lambda^{4}} .
\end{aligned}
$$

Thus, the profits of overseas suppliers and domestic retailers after coordination are

$$
\begin{aligned}
& \pi_{m}^{\mathrm{VMR} *}=\frac{(a-c)^{2} K_{2}}{8(1-\rho) K_{2}-3 \lambda^{2}}+\theta_{m}^{\mathrm{VMR} *}\left(\Delta \pi^{\mathrm{VMR}}\right), \\
& \pi_{r}^{\mathrm{VMR} *}=\frac{(a-c)^{2} K_{2}}{2\left[8(1-\rho) K_{2}-3 \lambda^{2}\right]}+\theta_{r}^{\mathrm{VMR} *}\left(\Delta \pi^{\mathrm{VMR}}\right) .
\end{aligned}
$$

\section{Example Analysis}

In order to further analyze and compare the rationality and effectiveness of decision-making in different cooperation modes, this paper verifies the above proposition by example analysis. Based on the investigated data, the relevant parameters can be set as the scale of domestic retailers' publicity activities $K_{2}=50$, potential market demand $a=100$, fixed transportation costs per unit product $c=5$, and the sensitivity of consumers to retailers' publicity $\lambda=0.6$. The value range of marginal transportation cost factor per unit product $\rho$ can be limited to range $[0.1,0.7]$.

Substituting the above parameters into the profit algebraic formula of supply chain members of Propositions 1-4 and the corresponding algebraic formula after coordination, as $\rho$ increases gradually in the range of values, the profits of the members of cross-border e-commerce will change accordingly. In order to observe the law of concrete change, the results of operations in different cooperative modes can be mapped to graphs to analyze the 

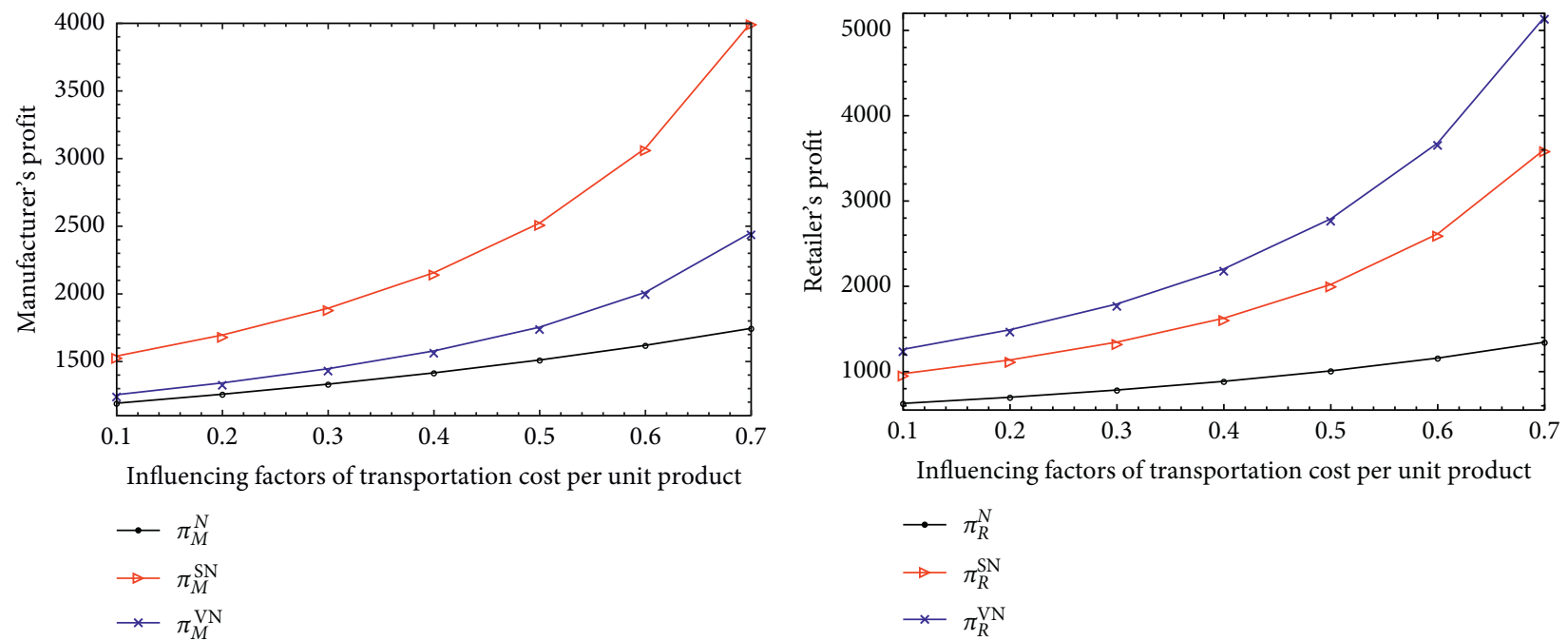

(a)

(b)

FIGURE 1: Impact of unit transport costs on member profits in the $N$ mode.

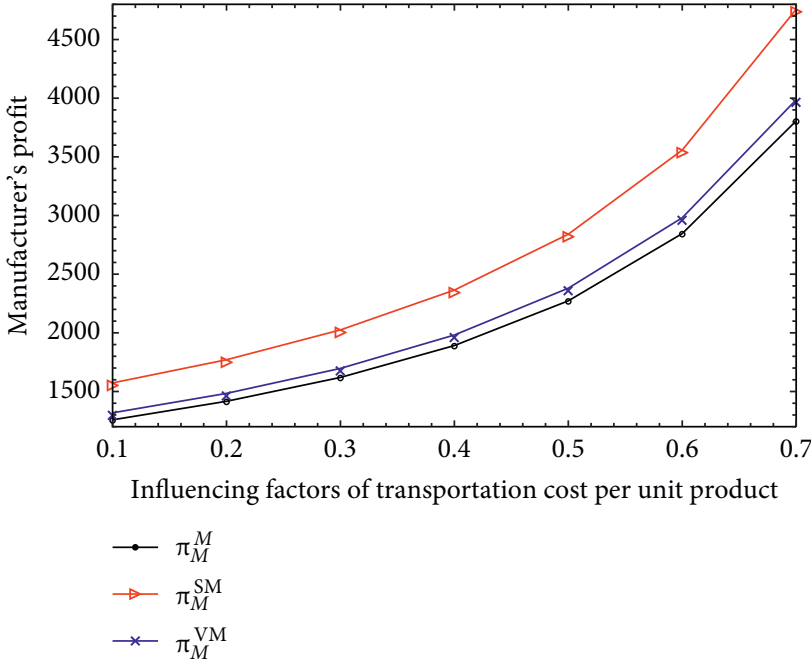

(a)

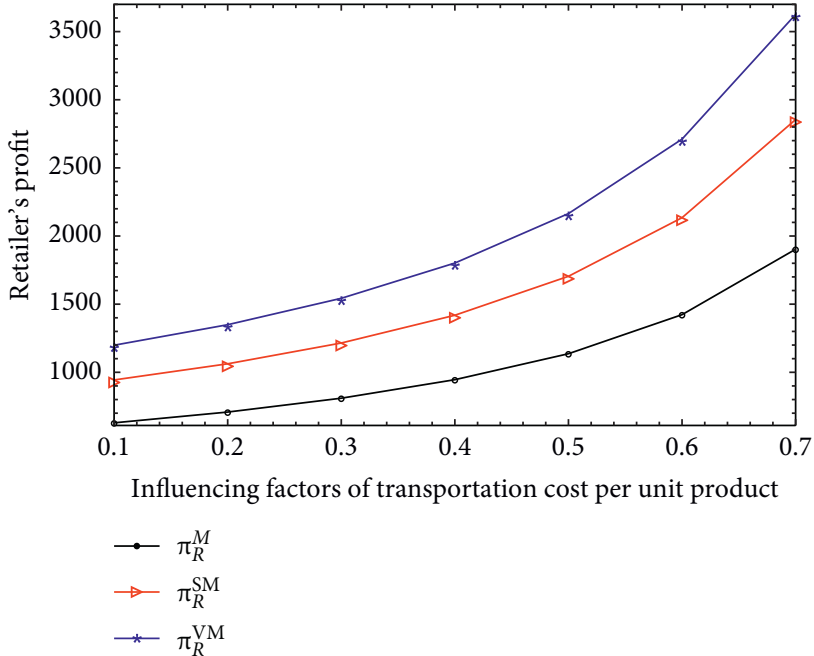

(b)

FIGURE 2: Impact of unit transport costs on member profits in the $M$ mode.

coordinating effect of the two coordination mechanisms, as shown in Figures 1-4.

It can be seen from Figures 1-4 that, under different cooperation modes, the Shapley value method and full cooperation revenue increment sharing coordination mechanism can improve the profits of overseas suppliers and domestic retailers. Firstly, overseas suppliers under different cooperation modes are more willing to choose the Shapley value method for profit redistribution, while domestic retailers are more willing to choose the full cooperation incremental revenue sharing mechanism for profit redistribution; secondly, the larger the unit transportation cost is, the more obvious the profit redistribution is; the impact of these two coordination mechanisms on the profits of cross-border e-commerce supply chain members will be different; Finally, under the two semi-cooperation modes of domestic retailers participating in the sharing of transportation costs of overseas suppliers, the profit coordination effect of full cooperation benefits is increasing, which is generally not important for the sharing mechanism of overseas suppliers. Taking different coordination mechanisms as units, the results can be drawn into tables to analyze the changing trend of profit under different cooperation modes before and after coordination, as shown in Tables 1 and 2.

It can be seen from Tables 1 and 2 that, under different cooperation modes, after the profits of supply chain members are coordinated by the Shapley value method and 

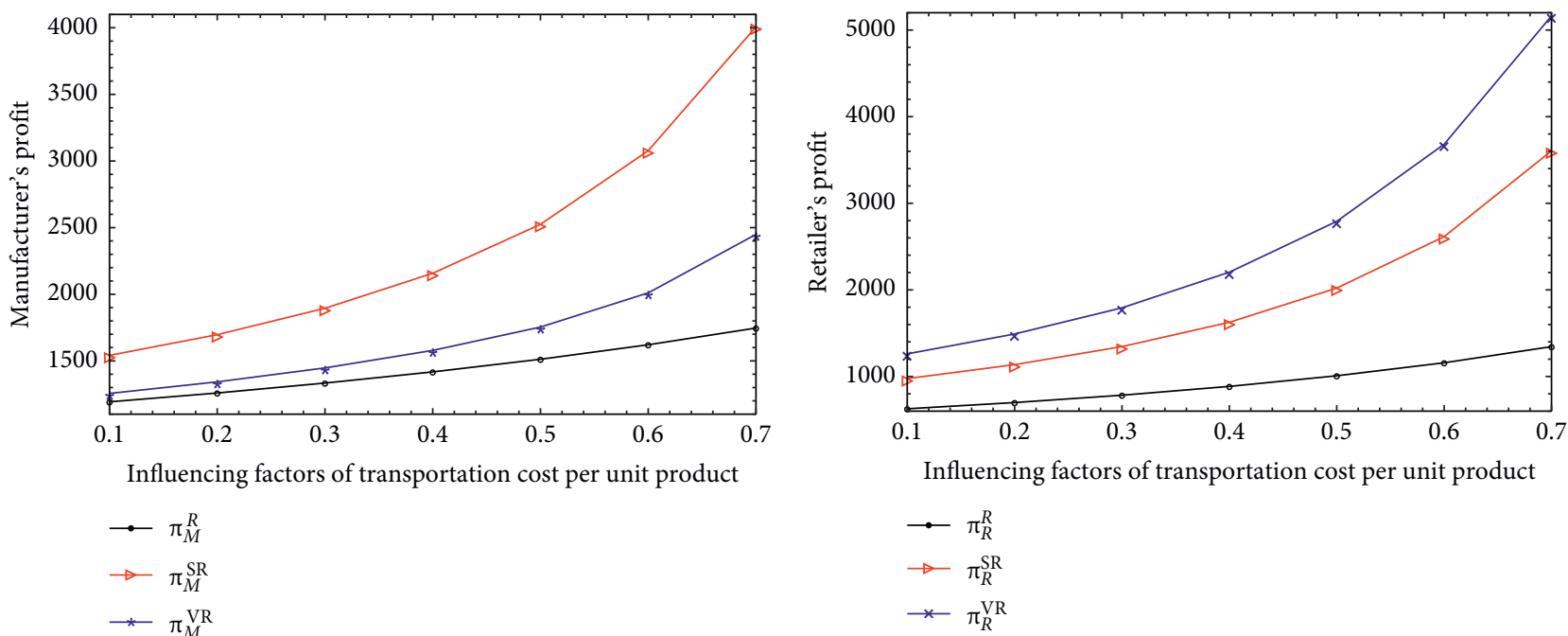

(a)

(b)

FIGURE 3: Impact of unit transport costs on member profits in the $R$ mode.
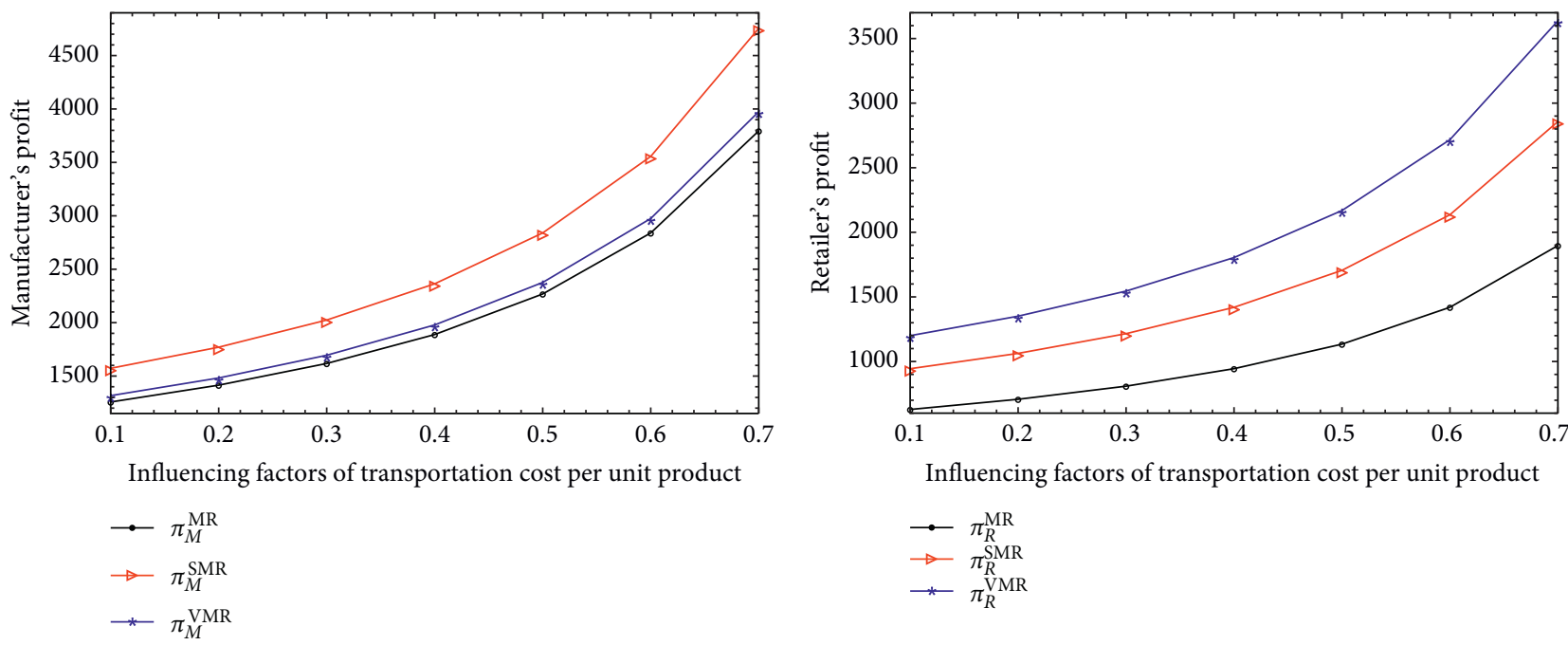$$
\begin{aligned}
& \rightarrow \pi_{R}^{\mathrm{MR}} \\
& \rightarrow \pi_{R}^{\mathrm{SMR}} \\
& \rightarrow \pi_{R}^{\mathrm{VMR}}
\end{aligned}
$$

(a)

(b)

Figure 4: Impact of unit transport costs on member profits in the MR mode.

TABle 1: Profits of members of different cooperation modes under the Shapley value method mechanism.

\begin{tabular}{|c|c|c|c|c|c|c|c|}
\hline & \multicolumn{7}{|c|}{$\rho$} \\
\hline & 0.1 & 0.2 & 0.3 & 0.4 & 0.5 & 0.6 & 0.7 \\
\hline$\overline{\pi_{M}^{\mathrm{SN} *}}$ & 1540.77 & 1696.06 & 1894.10 & 2156.76 & 2523.91 & 3076.45 & 4006.16 \\
\hline$\pi_{M}^{\mathrm{SM} *}$ & 1573.13 & 1770.66 & 2024.92 & 2364.45 & 2840.77 & 3557.41 & 4757.61 \\
\hline$\pi_{M}^{\mathrm{SR} *}$ & 1541.32 & 1696.66 & 1894.75 & 2157.46 & 2524.67 & 3077.27 & 4007.04 \\
\hline$\pi_{M}^{\mathrm{SMR} *}$ & 1572.82 & 1770.26 & 2024.40 & 2363.73 & 2839.74 & 3555.80 & 4754.73 \\
\hline$\pi_{R}^{\mathrm{SN} *}$ & 976.24 & 1137.00 & 1345.78 & 1626.36 & 2021.32 & 2615.40 & 3606.02 \\
\hline$\pi_{R}^{\mathrm{SM}} *$ & 943.88 & 1062.40 & 1214.95 & 1418.67 & 1704.46 & 2134.44 & 2854.57 \\
\hline$\pi_{R}^{\mathrm{SR} *}$ & 975.69 & 1136.41 & 1345.13 & 1625.66 & 2020.5 & 2614.58 & 3605.14 \\
\hline$\pi_{R}^{\text {SMR* }}$ & 944.19 & 1062.80 & 1215.48 & 1419.38 & 1705.49 & 2136.06 & 2857.45 \\
\hline
\end{tabular}


Table 2: Profits of members of different cooperative modes under the full cooperation income incremental mechanism.

\begin{tabular}{|c|c|c|c|c|c|c|c|}
\hline & \multicolumn{7}{|c|}{$\rho$} \\
\hline & 0.1 & 0.2 & 0.3 & 0.4 & 0.5 & 0.6 & 0.7 \\
\hline$\overline{\pi_{M}^{\mathrm{VN} *}}$ & 1255.33 & 1342.17 & 1446.97 & 1578.58 & 1754.20 & 2011.89 & 2453.71 \\
\hline$\pi_{M}^{\mathrm{VM} *}$ & 1318.33 & 1483.85 & 1696.90 & 1981.39 & 2380.48 & 2980.89 & 3986.34 \\
\hline$\pi_{M}^{\mathrm{VR} *}$ & 1255.69 & 1342.50 & 1447.20 & 1578.63 & 1753.80 & 2010.44 & 2449.38 \\
\hline$\pi_{M}^{\mathrm{VMR} *}$ & 1316.96 & 1482.22 & 1694.82 & 1978.53 & 2376.46 & 2974.62 & 3975.16 \\
\hline$\pi_{R}^{\mathrm{VN} *}$ & 1261.68 & 1490.89 & 1792.91 & 2204.53 & 2791.03 & 3679.96 & 5158.47 \\
\hline$\pi_{R}^{\mathrm{VM} *}$ & 1198.69 & 1349.21 & 1542.98 & 1801.73 & 2164.75 & 2710.96 & 3625.84 \\
\hline$\pi_{R}^{\mathrm{VR} *}$ & 1261.32 & 1490.56 & 1792.67 & 2204.49 & 2791.43 & 3681.41 & 5162.8 \\
\hline$\pi_{R}^{\mathrm{V} M R *}$ & 1200.06 & 1350.84 & 1545.06 & 1804.54 & 2168.77 & 2717.24 & 3637.02 \\
\hline
\end{tabular}

full cooperation revenue sharing mechanism, when the domestic retailers share the transportation costs of overseas suppliers, the suppliers get the maximum profits, while the domestic retailers get the maximum profits when the overseas suppliers and domestic retailers do not cooperate.

\section{Conclusion}

By constructing a cooperative game model of cross-border e-commerce supply chain composed of a single overseas supplier and a single domestic retailer, this paper explores how the propaganda strategy and transportation cost impact the pricing strategy of cross-border e-commerce. Meanwhile, the Shapley value method and the full cooperative income incremental sharing mechanism are introduced to redistribute the profits of supply chain members under different cooperation modes.

By verifying the decision results of different cooperation modes, the following conclusions can be drawn:

(1) If domestic retailers pursue lower wholesale prices, they need to share the transportation costs of overseas suppliers and attract more consumers at lower retail prices. Therefore, retailers sharing transport risks with overseas suppliers can significantly reduce the cost of cross-border e-commerce to expand customer groups to enhance product sales and ultimately achieve an increase in profitability.

(2) The whole cross-border e-commerce supply chain is pursuing the most efficient commodity promotion strategy, and it needs two-way cooperation between overseas suppliers and domestic retailers; that is, domestic retailers share the transportation costs of overseas suppliers and overseas suppliers share the publicity costs of domestic retailers. This indicates that, in the cross-border e-commerce supply chain, domestic retailers share overseas suppliers as a winwin strategy.

(3) When the members of cross-border e-commerce supply chain choose the mode of first coordination and then cooperation, overseas suppliers generally choose retailers to share the total transportation costs of suppliers, while domestic retailers choose the non-cooperation mode; when the members of the cross-border e-commerce supply chain choose the mode of cooperation before coordination, most of the overseas suppliers will choose the Shapley value method to redistribute the profits, while the domestic retailers will choose the full cooperative income incremental sharing mechanism to redistribute the profits.

(4) Overseas suppliers under different cooperation modes are more willing to choose the Shapley value method for profit redistribution, while domestic retailers are more willing to choose the full cooperative income incremental sharing mechanism for profit redistribution. In addition, the greater the unit transportation cost is, the more obvious the effect of the two coordination mechanisms on the profits of the members of the cross-border e-commerce supply chain will be.

Although our article has made a lot of contributions around these problems, there are still many places to continue to study. When the demand is uncertain, whether the same result will be obtained and what kind of change will happen when the supply chain structure changes are very interesting research issues.

\section{Data Availability}

There are not empirical data in this paper. The equilibrium solution of the model is obtained by Mathematics software.

\section{Conflicts of Interest}

The authors declare that they have no conflicts of interest.

\section{Acknowledgments}

This work was sponsored by the National Natural Science Foundation of China (Grant nos. 72072112, 71602114, 72002125, and 72001135), Shanghai Rising-Star Program (Grant no. 19QA1404200), Shanghai Sailing Program (Grant nos. 19YF1418800 and 20YF1416600), Middle-Aged and Young Teachers' Basic Ability Promotion Project of Guangxi (Grant no. 2020KY04036), and Talent Introduction Research Project of Guangxi University for Nationalities (Grant no. 2018SKQD16). 


\section{References}

[1] L. Xu, Z. Di, and J. Chen, "Evolutionary game analysis on behavior strategies of multiple stakeholders in maritime shore power system," Ocean \& Coastal Management, vol. 202, Article ID 105508, 2021.

[2] L. Xu, J. Shi, and J. H. Chen, "Platform encroachment with price matching: introducing a self-constructing online platform into the sea-cargo market," Computers \& Industrial Engineering, vol. 156, Article ID 107266, 2021.

[3] Y. Malekian and M. Rasti-Barzok, "A game theoretic approach to coordinate price promotion and advertising policies with reference price effects in a two-echelon supply chain," Journal of Retailing and Consumer Services, vol. 51, pp. 114-128, 2019.

[4] J. Xie, L. Liang, L. Liu et al., "Coordination contracts of dualchannel with cooperation advertising in closed-loop supply chains," International Journal of Production Economics, vol. 183, pp. 528-538, 2017.

[5] J. Chaab and M. Rasti-Barzoki, "Cooperative advertising and pricing in a manufacturer-retailer supply chain with a general demand function: a game-theoretic approach," Computers \& Industrial Engineering, vol. 99, pp. 112-123, 2017.

[6] T. Y. Chan, C. Narasimhan, and Y. Yoon, "Advertising and price competition in a manufacturer-retailer channel," International Journal of Research in Marketing, vol. 34, no. 3, pp. 694-716, 2017.

[7] J. Song, F. Li, D. Wu et al., "Supply chain coordination through integration of innovation effort and advertising support," Applied Mathematical Modelling, vol. 49, pp. 108123, 2017.

[8] P. Rodríguez-Torrico, R. S. J. Cabezudo, and S. San-Martín, "Tell me what they are like and I will tell you where they buy. An analysis of omnichannel consumer behavior," Computers in Human Behavior, vol. 68, pp. 465-471, 2017.

[9] A. James and V. W. Eric, "Trade costs," Journal of Economic Literature, vol. 42, no. 3, pp. 691-751, 2004.

[10] X. Liang and L. Liang, "Retailer-led cross-border dual-channel supply chain pricing decision under the change of tariff and cost," China Management Science 2020, in Chinese.

[11] Y. Zhang, "A study on the cost control of cross-border E-commerce logistics," National Circulation Economy, no. 33, pp. 18-19, 2018, in Chinese.

[12] D. Zi, "Cost control of cross-border E-commerce logistics under overseas warehouse mode," Logistics Technology, vol. 34, no. 16, pp. 175-180, 2015, in Chinese.

[13] Q. Y. Peng, C. X. Wang, and L. Xu, "Emission abatement and procurement strategies in a low-carbon supply chain with option contracts under stochastic demand," Computers \& Industrial Engineering, vol. 144, Article ID 106502, 2020.

[14] L. Xu, C. X. Wang, and J. J. Zhao, "Decision and coordination in the dual-channel supply chain considering cap-and-trade regulation," Journal of Cleaner Production, vol. 197, pp. 551$561,2018$.

[15] T. Dai, S. H. Cho, and F. Zhang, "Contracting for on-time delivery in the US influenza vaccine supply chain," Manufacturing \& Service Operations Management, vol. 18, pp. 332-346, 2016.

[16] X. Liu, Q. Gou, L. Alwan et al., "Option contracts: a solution for overloading problems in the delivery service supply chain," Journal of Operational Research Society, vol. 67, pp. 187-197, 2016.

[17] Q. Wang and D. Zhao, "Co-operative strategies on emission reduction and promotion of two-level supply chain," Control and Decision-Making, vol. 29, no. 2, pp. 307-314, 2014, in Chinese.

[18] J. Chen, L. Liang, D. Yao et al., "Price and quality decisions in dual-channel supply chains," European Journal of Operational Research, vol. 259, no. 3, pp. 935-948, 2017. 